\title{
Modeling studies on divorced eutectic formation of high pressure die cast magnesium alloy
}

\author{
Meng-wu Wu ${ }^{1,2}$, * Lin Hua ${ }^{1,2}$ and Shou-mei Xiong ${ }^{3}$ \\ 1. Hubei Key Laboratory of Advanced Technology for Automotive Components, Wuhan University of Technology, Wuhan 430070, China; \\ 2. Hubei Collaborative Innovation Center for Automotive Components Technology, Wuhan 430070, China; \\ 3. School of Materials Science and Engineering, Tsinghua University, Beijing 100084, China
}

\begin{abstract}
The morphology and content of the divorced eutectic in the microstructure of high pressure die casting (HPDC) magnesium alloy have a great influence on the final performance of castings. Based on the previous work concerning simulation of the nucleation and dendritic growth of primary $\alpha-M g$ during the solidification of magnesium alloy under HPDC process, an extension was made to the formerly established CA (Cellular Automaton) model with the purpose of modeling the nucleation and growth of $\mathrm{Mg}-\mathrm{Al}$ eutectic. With a temperature field and solute field obtained during simulation of the primary $\alpha-\mathrm{Mg}$ dendrites as the initial condition of the modified CA model, modeling of the Mg-Al eutectic with a divorced morphology was achieved. Moreover, the simulated results were in accordance with the experimental ones regarding the distribution and content of the divorced eutectic. Taking a "cover-plate" die casting with AM60 magnesium alloy as an example, the rapid solidification with a high cooling rate at the surface layer of the casting led to a fine and uniform grain size of primary a-Mg, while the divorced eutectic at the grain boundary revealed a more dispersed and granular morphology. Islands of divorced eutectic were observed at the central region of the casting, due to the existence of ESCs (Externally Solidified Crystals) which contributed to a coarse and non-uniform grain size of primary $\alpha-\mathrm{Mg}$. The volume percentage of the eutectic $\beta-\mathrm{Mg}_{17} \mathrm{Al}_{12}$ phase is about $2 \%-6 \%$ in the die casting as a whole. The numerical model established in this study is of great significance to the study of the divorced eutectic in the microstructure of die cast magnesium alloy.
\end{abstract}

Key words: magnesium alloy; high pressure die casting; divorced eutectic; microstructure simulation

CLC numbers: TP391.99/TG146.22Ｄocument code: A Article ID) 1672-6421(2018)01-058-08

\begin{abstract}
A s the lightest known structural metals, magnesium alloys have attracted much attention due to their superior properties such as low density, high specific strength, excellent castability, good machinability and recyclability ${ }^{[1,2]}$. Magnesium alloys have been widely used in automotive, aerospace and 3C (computer, communication and consumer electronics) industries to replace steel, cast iron and even aluminum alloy ${ }^{[3]}$. The high pressure die casting (HPDC) process is a netshape or near net-shape process with the advantages of high efficiency, considerable economic benefit and high precision of the product size. These remarkable advantages make the HPDC process particularly suitable for various complex productions with magnesium alloys, and generally, magnesium alloy parts are mainly formed by the HPDC process $^{[4]}$.

The performance of magnesium alloy die castings
\end{abstract}

\section{*Lin Hua}

Male, born in 1962, Ph.D., Professor. Research interests: advanced manufacturing processes and technologies for automotive components.

E-mail: hualin@whut.edu.cn

Received: 2017-09-28; Accepted: 2018-01-02 is strongly influenced by the microstructure formed during solidification. One of the key microstructure characteristics of die cast magnesium alloy is the appearance of relatively coarse dendrites which have been called "ESCs (Externally Solidified Crystals)" at the cross section of the castings. As for the microstructure characteristics and formation mechanism of the ESCs, systematic experimental studies have been carried out by the authors ${ }^{[5-7]}$ and some metallurgists ${ }^{[8-10]}$. Especially combined with the research hotspot of microstructure simulation during various solidification processes $^{[11-13]}$, a large amount of work has also been conducted regarding simulation of the dendritic growth of $\alpha-\mathrm{Mg}$ with hcp (hexagonal close-packed) crystal structure $^{[14,15]}$, and also microstructure simulation of die cast magnesium alloy considering the nucleation and growth of the ESCs ${ }^{[16]}$.

For most commercially available magnesium alloys for the HPDC process, the element $\mathrm{Al}$ is the dominant alloying element. Another key microstructure characteristic of die cast $\mathrm{Mg}-\mathrm{Al}$ alloy is the appearance of divorced $\mathrm{Mg}$-Al eutectic in die castings. Existing studies have demonstrated that the constitution, 
morphology and distribution of the divorced $\mathrm{Mg}-\mathrm{Al}$ eutectic remarkably affect the performance of die castings, particularly the ductility, corrosion resistance, high temperature strength and creep resistance ${ }^{[17,18]}$. In view of the above situation, indepth experimental studies have been conducted on the microstructure characteristics of the divorced eutectic of die cast magnesium alloy ${ }^{[19-21]}$. However, few simulation works have been reported on formation of the divorced $\mathrm{Mg}$ - $\mathrm{Al}$ eutectic until now. Modeling studies on the divorced $\mathrm{Mg}-\mathrm{Al}$ eutectic of die cast magnesium alloy are extremely meaningful in controllling the microstructure formation, and consequently, improving the properties of magnesium alloy die castings. Using the CA method, Zhu et al. ${ }^{[22,23]}$ simulated the microstructure evolution of spheroidal graphite cast iron during divorced eutectic solidification, and then discussed the effect of cooling rate on the size and distribution of graphite nodules.

Based on the previous work about simulation of the nucleation and dendritic growth of primary $\alpha-\mathrm{Mg}$ during solidification of magnesium alloy under the HPDC process, an extension was made to the formerly developed CA model to take the nucleation and growth of $\mathrm{Mg}-\mathrm{Al}$ eutectic into account. By applying the modified CA model, simulations were carried out on the morphology and distribution of $\mathrm{Mg}-\mathrm{Al}$ eutectic in magnesium alloy die castings, and a comparison was also made between the simulated and the experimental results.
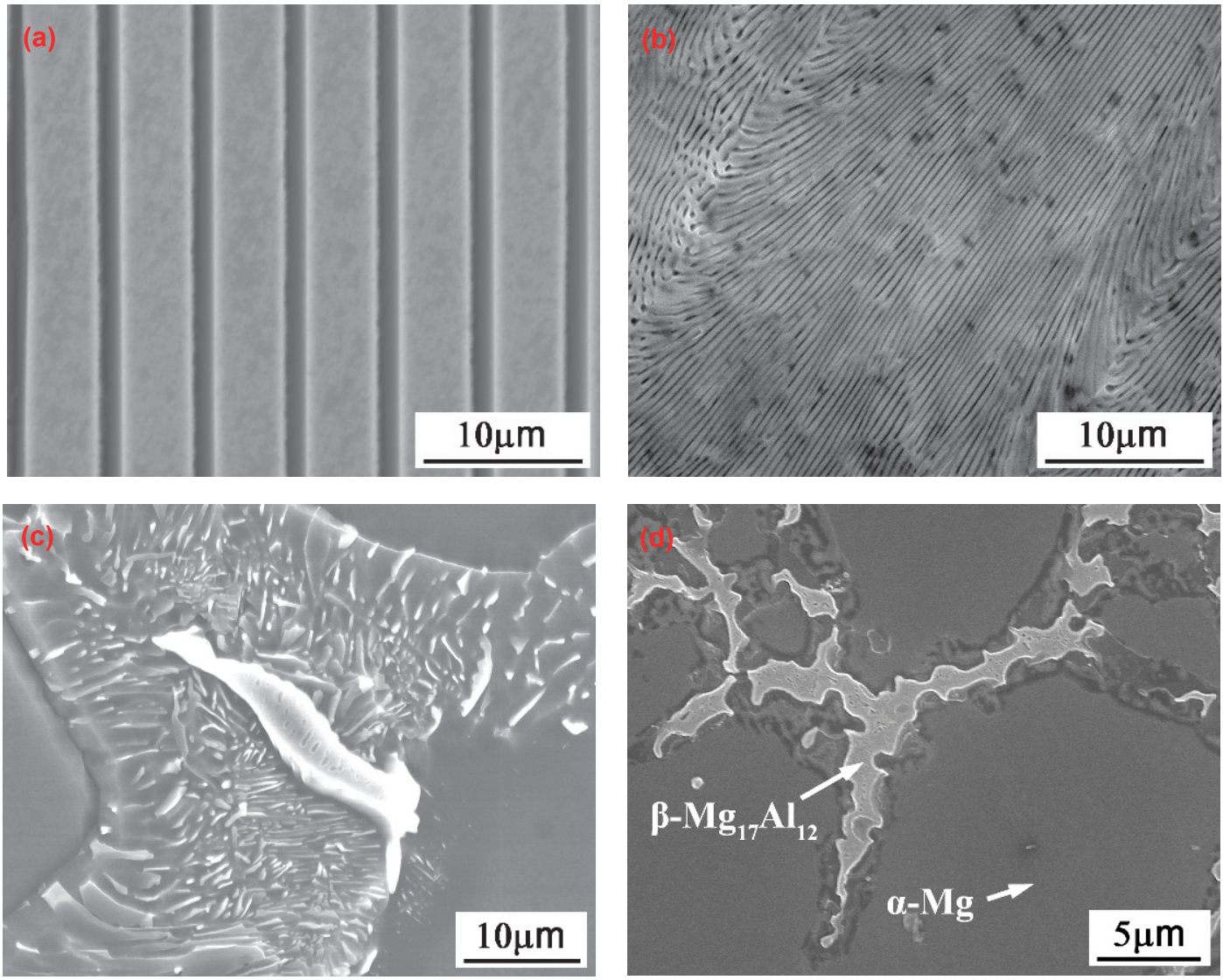

Fig. 1: Morphology of eutectic phases in microstructure of magnesium alloys with different alloy compositions and cooling rates: (a) Mg-32.3wt.\%Al alloy under directional solidification with a withdrawal rate of $3 \mu \mathrm{m} \cdot \mathrm{s}^{-1}$, (b) Mg-32.3wt.\%Al alloy with permanent mould casting, (c) ingot of AM60 magnesium alloy, (d) die cast AM60 magnesium alloy 
of the experimental condition and procedure could be found in references ${ }^{[21,24]}$. It can be seen from Fig. 1(a) that the two eutectic phases grew cooperatively and competitively with a regular lamellar structure in the microstructure of Mg-32.3 wt.\% Al alloy under directional solidification with a withdrawal rate of $3 \mu \mathrm{m} \cdot \mathrm{s}^{-1}$, whilst a fibrous morphology of the Mg-Al eutectic could be observed in the casting of Mg-32.3wt.\% Al alloy with permanent mould [Fig. 1(b)]. In the microstructure of AM60 magnesium alloy ingot [Fig. 1(c)] and die cast AM60 magnesium alloy [Fig. 1(d)], the two eutectic phases revealed a divorced morphology. To be exact, fully divorced $\mathrm{Mg}-\mathrm{Al}$ eutectics were formed in the microstructure of die cast AM60 magnesium alloy. In this case, the eutectic $\alpha-\mathrm{Mg}$ nucleated and grew attached to the primary $\alpha-\mathrm{Mg}$, while the eutectic $\beta-\mathrm{Mg}_{17} \mathrm{Al}_{12}$ nucleated and grew independently. Except for the fully divorced $\mathrm{Mg}-\mathrm{Al}$ eutectic, partially divorced eutectic appeared in the microstructure of AM60 magnesium alloy ingot, and plenty of lamellae of $\beta-\mathrm{Mg}_{17} \mathrm{Al}_{12}$ phases were precipitated around the divorced eutectic. It can be noted by comparison that a lower $\mathrm{Al}$ content of the $\mathrm{Mg}-\mathrm{Al}$ alloy and an increase of the cooling rate both led to a more divorced morphology of the $\mathrm{Mg}-\mathrm{Al}$ eutectic, from lamellar to fibrous, partially divorced, and finally fully divorced.

\section{Numerical model and algorithms}

According to the requirement of modeling the actual microstructure evolution of die cast magnesium alloy, the $\mathrm{CA}$ method was used to simulate the formation of $\mathrm{Mg}-\mathrm{Al}$ eutectic at the last stage of solidification in the die cavity, since it has the attractive advantages of simplicity of formulation and computational convenience when implemented to solve phase transition problems with an acceptable computational efficiency ${ }^{[11]}$. Based on the precise temperature datum of the die measured by a general temperature measurement unit, an inverse heat transfer model was applied to calculate the temperature field of the molten melt in the die cavity. Algorithms and procedure in detail of the inverse calculation could be found in reference [14]. As an extension of the previous work about simulation of the nucleation and dendritic growth of primary $\alpha-\mathrm{Mg}$ during solidification in the die cavity, the previously simulated results were treated as the initial condition for simulations in the present work. At the last stage of solidification of die cast magnesium alloy, when the temperature of the melt went below the eutectic temperature, and the solute concentration in the interdendritic liquid was up to the eutectic composition, eutectic nucleation and growth began.

\subsection{Solute transport}

During solidification of the two eutectic phases $\alpha-\mathrm{Mg}$ and $\beta-\mathrm{Mg}_{17} \mathrm{Al}_{12}$, solute diffusion plays an important role in determining the eutectic growth morphology and the corresponding microstructure characteristics. As the eutectic solidification proceeded, the solute accumulated at the solidification front of eutectic $\alpha-\mathrm{Mg}$ due to the solute rejection associated with the solidification of eutectic $\alpha-\mathrm{Mg}$. On the other hand, a solute-depleted region existed ahead of eutectic
$\beta-\mathrm{Mg}_{17} \mathrm{Al}_{12}$ because of the solute absorption associated with the solidification of eutectic $\beta-\mathrm{Mg}_{17} \mathrm{Al}_{12}$. For the calculation of solute field, solidification equilibrium among the two eutectic phases and the liquid phase was assumed, that is, $\mathrm{L} \rightarrow \alpha\left(C_{\alpha 0}\right)$ $+\beta\left(C_{\beta 0}\right)$. Meanwhile, the effect of convection on the solute field was not taken into account, and the solute diffusion in the two solid phases was also negligible. Therefore, the governing equation for solute redistribution in liquid is as follows:

$\frac{\partial C_{\mathrm{L}}}{\partial t}=\frac{\partial}{\partial x}\left(D_{\mathrm{L}} \frac{\partial C_{\mathrm{L}}}{\partial x}\right)+\frac{\partial}{\partial y}\left(D_{\mathrm{L}} \frac{\partial C_{\mathrm{L}}}{\partial y}\right)+\left(C_{\mathrm{L}}-C_{\alpha 0}\right) \frac{\partial f_{\mathrm{s}, \alpha}}{\partial t}+\left(C_{\mathrm{L}}-C_{\beta 0}\right) \frac{\partial f_{\mathrm{s}, \beta}}{\partial t}$

where $C_{\mathrm{L}}$ is the solute concentration of the liquid, $t$ is the time, and $D_{\mathrm{L}}$ is the solute diffusion coefficient in liquid. $C_{\alpha 0}$ and $C_{\beta 0}$ denote the solute concentrations, whereas $f_{\mathrm{s}, \alpha}$ and $f_{\mathrm{s}, \beta}$ represent the solid fractions, of the two eutectic phases $\alpha-\mathrm{Mg}$ and $\beta-\mathrm{Mg}_{17} \mathrm{All}_{2}$, and $x$ and $y$ denote the directions of the Cartesian coordinate system in two dimensions. Since the solutal diffusivity is usually several orders of magnitude smaller than the thermal diffusivity, a zero-flux boundary condition was imposed to solve Eq. (1) with an explicit finite difference scheme. The time step was determined by the solute diffusion coefficient in liquid and the growth velocities of the two eutectic phases.

\subsection{Growth kinetics and capturing rule}

As the temperature of the melt went below the eutectic temperature, solidification of the two eutectic phases began under the driving force of the local undercooling $\Delta T$. According to the existing analytical models and experimental results ${ }^{[25-27]}$, the growth velocities of the two eutectic phases can be calculated as:

$$
V=a \cdot \Delta T^{2}
$$

where $a$ is the growth kinetics coefficient, whose value was chosen to be $10^{-5} \mathrm{~m} \cdot\left(\mathrm{s} \cdot \mathrm{K}^{2}\right)^{-1}$ for the calculation of the growth velocities of both the two eutectic phases ${ }^{[26]}$. The local undercooling of the interface cell can be given by:

$$
\Delta T\left(t_{n}\right)=T_{\mathrm{E}}-T\left(t_{n}\right)+m_{i} \cdot\left[C\left(t_{n}\right)-C_{\mathrm{E}}\right]-\Gamma_{i} K_{i}\left(t_{n}\right)
$$

where $\Delta T\left(t_{n}\right), T\left(t_{n}\right)$ and $C\left(t_{n}\right)$ are the local undercooling, temperature and solute concentration, respectively, of the interface cell at time $t_{n} . T_{\mathrm{E}}$ and $C_{\mathrm{E}}$ represent the eutectic temperature and eutectic composition, respectively. $m_{i}$ denotes the liquidus slope, while $\Gamma_{i}$ is the Gibbs-Thomson coefficient. For the two eutectic phases, the values of $m_{i}$ and $\Gamma_{i}$ are different with respect to each other. In the present work, $m_{\alpha}<0, m_{\beta}>0$. $K_{i}\left(t_{n}\right)$ is the mean curvature of the interface cell at time $t_{n}$. A counting method was used to calculate $K_{i}\left(t_{n}\right)$, which can be expressed as ${ }^{[12]}$ :

$$
K_{i}\left(t_{n}\right)=\frac{1}{\Delta s}\left(1-2 \frac{f_{\mathrm{s}, i}+\sum_{j=1}^{n} f_{\mathrm{s}, i}(j)}{n+1}\right)
$$

where $\Delta s$ is the size of the CA cell, $f_{\mathrm{s}, i}$ and $f_{\mathrm{s}, i}(j)$ denote the solid fractions of phase $i$ ( $\alpha$ or $\beta$ ) of the interface cell and the neighboring cells, respectively. $n$ is the number of neighboring cells, which is equal to 8 in two dimensions, since only cells of 
the first layer were defined as neighboring cells in the present CA model. It is worth mentioning that due to the fact that each interface cell is further specified as $\alpha /$ liquid interface cell or $\beta /$ liquid interface cell, the calculation of the mean curvature of the $\alpha /$ liquid interface cell and $\beta /$ liquid interface cell should be done separately.

As a liquid cell is transferred into an interface cell by nucleation or a capturing process, the solid fraction of the cell begins to increase, which can be calculated via:

$$
\delta f_{\mathrm{s}}=\frac{V\left(t_{n}\right) \cdot \delta t}{l}
$$

where $\delta f_{s}$ denotes the solid fraction increment of the interface cell during the time step $\delta t, V\left(t_{n}\right)$ represents the growth velocity of the interface cell at time $t_{n}$, and $l$ is the distance between the center of the current interface cell and the center of the "parent" solid cell. When the solid fraction of the interface cell increases from 0 to 1 , the cell changes into a solid cell. To be specific, if the interface cell is an $\alpha$ /liquid interface cell, the cell is then converted into an $\alpha$ solid cell, or if the original is a $\beta /$ liquid interface cell, then the cell changes into a $\beta$ solid cell. Since the cell becomes a solid state, capturing of the neighboring liquid cells into new interface cells begins. In two dimensions, a capturing rule was established that if more than three cells had the " $\alpha$ solid" state in the eight neighboring cells around the liquid cell being captured, then the liquid cell would change into an $\alpha /$ liquid interface cell. Similarly, if more than three cells have the " $\beta$ solid" state in the eight neighboring cells around the target liquid cell, the liquid cell is then converted into a $\beta /$ liquid interface cell. Otherwise, the liquid cell will not be captured, and its state will remain unchanged ${ }^{[28]}$. Based on the capturing process and solid fraction increment of the inteface cells, the solidification front advances. And in this manner, a remarkable convenience also can be found that no specific tracking process for the solidification interface and morphology is demanded in the present CA model.

\subsection{Nucleation of two eutectic phases}

As for the nucleation of the two eutectic phases $\alpha-\mathrm{Mg}$ and $\beta-\mathrm{Mg}_{17} \mathrm{Al}_{12}$, a nucleation model was adopted which was proposed by Charbon et al. ${ }^{[13]}$ for simulation of the microstructure evolution of grey cast iron during eutectic solidification. Here, the eutectic nucleation density, $N$, is correlated with the nucleation undercooling of the melt, $\Delta T_{N}$, in the form of a functional relationship as follows:

$$
N=A_{n} \cdot \Delta T_{N}{ }^{b}
$$

where $A_{n}$ and $b$ both are nucleation parameters, whose values were chosen to be $4.65 \times 10^{5}$ and 1.22 , respectively ${ }^{[13]}$. Different from the local undercooling, $\Delta T\left(t_{n}\right)$, during calculation of the growth kinetics of the two eutectic phases, the value of nucleation undercooling, $\Delta T_{N}$, is just the difference between the eutectic temperature, $T_{\mathrm{E}}$, and the temperature of the melt. Once the nucleation number of the two eutectic phases is calculated according to Eq. (6), nulcei are set at certain locations of the calculation domain. Since each nucleus in fact includes two eutectic phases, $\alpha-\mathrm{Mg}$ and $\beta-\mathrm{Mg}_{17} \mathrm{Al}_{12}$, a corresponding treatment was proposed in the CA model that each nucleus was constructed by two CA cells, one represented phase $\alpha-\mathrm{Mg}$, and the other $\beta-\mathrm{Mg}_{17} \mathrm{Al}_{12}$. On the basis of the nucleation and growth mechanisms of divorced eutectic, liquid cells next to the primary $\alpha-\mathrm{Mg}$ and with high solute concentration were randomly selected and converted into the eutectic $\alpha /$ liquid interface cells. Meanwhile, liquid cells a certain distance from the eutectic $\alpha /$ liquid interface cells would change into eutectic $\beta /$ liquid interface cells.

\section{Simulation results and discussion}

By applying the established nucleation and growth models of $\mathrm{Mg}-\mathrm{Al}$ eutectic mentioned above, and taking the previously simulated results of dendritic growth of primary $\alpha-\mathrm{Mg}$ during solidification in the die cavity as the initial condition, modeling of the eutectic formation in the microstructure of die cast AM60 magnesium alloy was conducted. Treated as a binary alloy for simplification, the parameters and physical properties of AM60 magnesium alloy used in the present simulations are shown in Table $1^{[15,24]}$. Figure 2 shows the schematic diagram of a "coverplate" die casting with biscuit, runners and overflows used for

Table 1: Parameters used in current simulations ${ }^{[15,24]}$

$\begin{array}{cc}\text { Parameter } & \text { Value } \\ \text { Eutectic temperature, } T_{\mathrm{E}}(\mathrm{K}) & 710 \\ \text { Eutectic composition, } C_{\mathrm{E}}(\mathrm{wt} . \%) & 32.3 \\ \text { Solute concentration of } \alpha \text { phase, } C_{\mathrm{a} 0}(\mathrm{wt} . \%) & 12.7 \\ \text { Solute concentration of } \beta \text { phase, } C_{\beta 0}(\mathrm{wt} . \%) & 40.2 \\ \text { Liquidus slope of } \alpha \text { phase, } m_{\mathrm{a}}\left(\mathrm{K} \cdot \mathrm{wt} . \%^{-1}\right) & -6.59 \\ \text { Liquidus slope of } \beta \text { phase, } m_{\beta}\left(\mathrm{K} \cdot \mathrm{wt} . \%^{-1}\right) & 2.15 \\ \text { Solute diffusion coefficient in liquid, } D_{\mathrm{L}}\left(\mathrm{m}^{2} \cdot \mathrm{s}^{-1}\right) & 3 \times 10^{-9} \\ \text { Gibbs-Thomson coefficient of } \alpha \text { phase, } \Gamma_{\mathrm{\alpha}}(\mathrm{K} \cdot \mathrm{m}) & 1.5 \times 10^{-7} \\ \text { Gibbs-Thomson coefficient of } \beta \text { phase, } \Gamma_{\beta}(\mathrm{K} \cdot \mathrm{m}) & 1.5 \times 10^{-7}\end{array}$

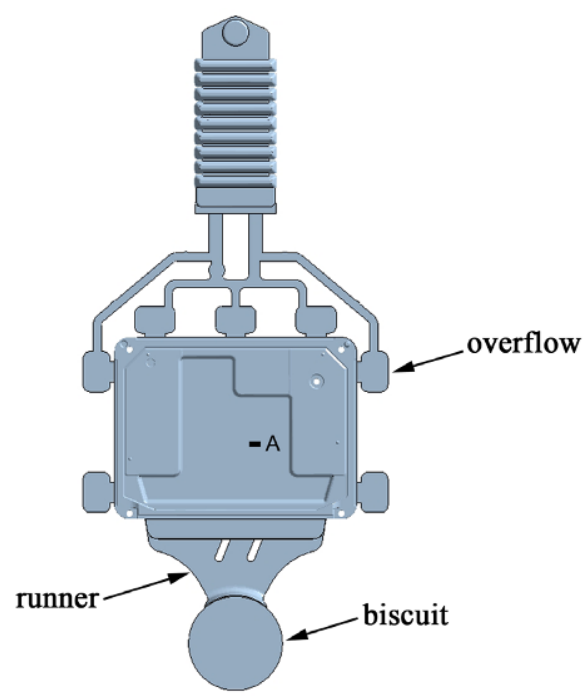

Fig. 2: Complete "cover-plate" die casting with biscuit, runners and overflows 
experimental and modeling studies. With a length of $180 \mathrm{~mm}$ and a width of $138 \mathrm{~mm}$, the thickness of the "cover-plate" was about 1.9-2.7 $\mathrm{mm}$. Under the cold-chamber HPDC process, the standard process parameters of the die casting experiment were as follows: mould temperature ( $453 \mathrm{~K})$, pouring temperature (973 $\mathrm{K}$ ), slow shot phase plunger velocity $\left(0.15 \mathrm{~m} \cdot \mathrm{s}^{-1}\right)$, fast shot phase plunger velocity $\left(4.0 \mathrm{~m} \cdot \mathrm{s}^{-1}\right)$, casting pressure $(77 \mathrm{MPa})$, and filling fraction of the shot sleeve $(18.3 \%)$. The metallographic piece was taken from location "A" as shown in Fig. 2 with a thickness of $1.9 \mathrm{~mm}$.

\subsection{Morphology of Mg-Al eutectic}

With a calculation domain consisting of $570 \times 430$ square cells and with a cell size of $1 \mu \mathrm{m}$, Fig. 3 shows the simulated microstructure evolution of the $\mathrm{Mg}-\mathrm{Al}$ eutectic at the central region of the"cover-plate" die casting. It can be seen from Fig. 3(a) that at the early stage of eutectic solidification, the solidification structure of die cast AM60 magnesium alloy was composed of a mixture of coarse ESCs and fine grains of primary $\alpha-\mathrm{Mg}$, while no obvious eutectic nucleation and growth were observed in the interdendritic liquid. As the temperature of the melt lowered and the eutectic solidification proceeded, eutectic nucleation occured at the grain boundaries of primary $\alpha-\mathrm{Mg}$ [Fig. 3(b)]. Furthermore, the eutectic phases continued to grow and finally revealed an island-like morphology as shown in Figs. 3(c) and 3(d). Moreover, it could be noted that most of the $\mathrm{Mg}-\mathrm{Al}$ eutectic nucleated and grew in the regions near the coarse ESCs. The cause of this phenomenon can be
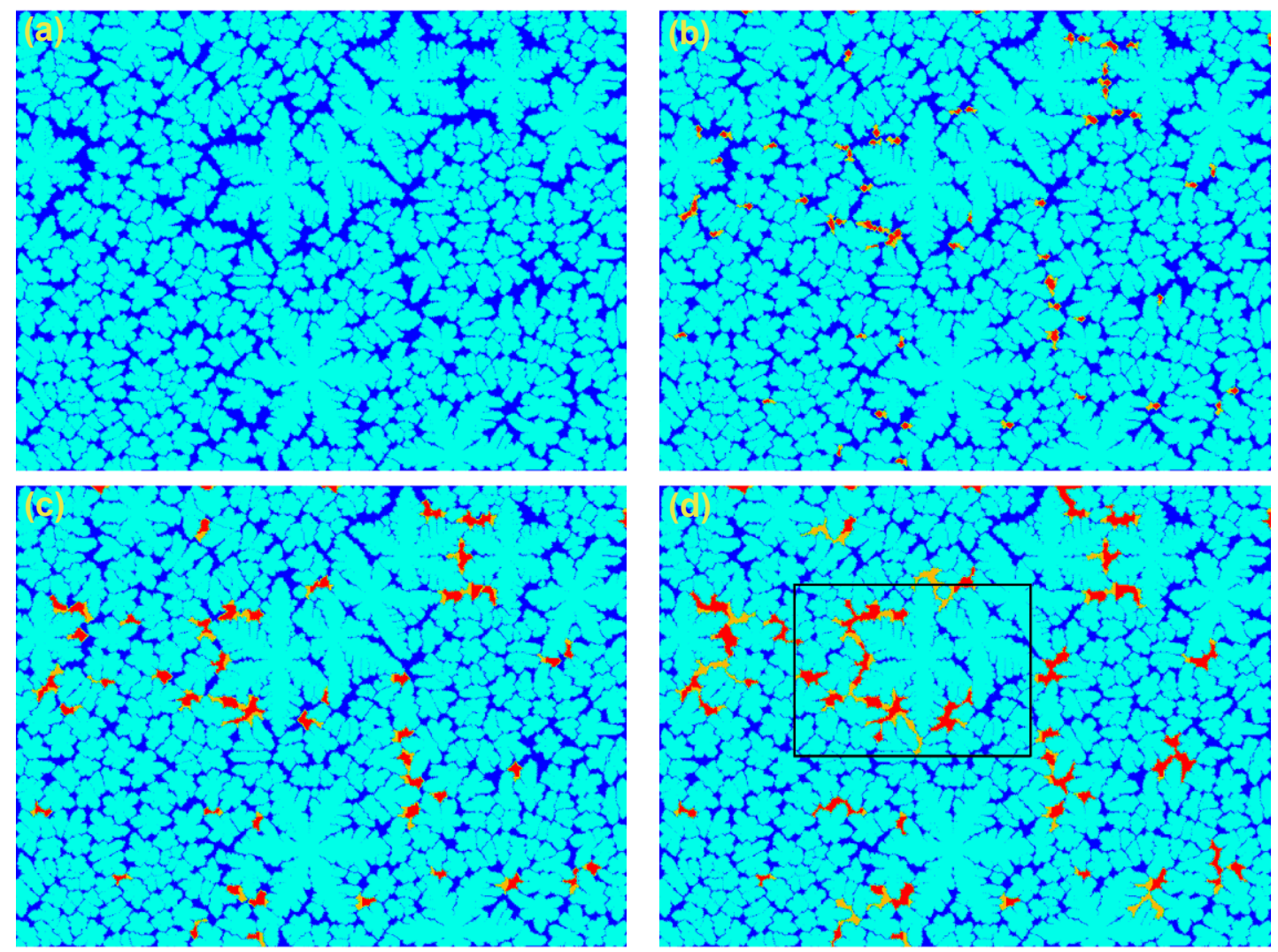

Fig. 3: Simulated microstructure evolution of Mg-Al eutectic at the central region of "cover-plate" die casting: (a) $0 \mathrm{~s}$, (b) $0.18 \mathrm{~s}$, (c) $0.28 \mathrm{~s}$, (d) $0.76 \mathrm{~s}$ (the time was counted at the moment when the temperature of melt went below the eutectic temperature)

described as follows: due to the solute rejection associated with the solidification of primary $\alpha-\mathrm{Mg}$, the solute concentration was relatively high in the interdendritic liquid near the coarse ESCs, while the eutectic phases were inclined to nucleate and grow in these regions. Meanwhile, owing to the splitting effect of coarse ESCs on the melt, the eutectic phases solidified in the interdendritic liquid and then revealed an island-like morphology.

In order to observe the growth morphology of the two eutectic phases carefully, Fig. 4 gives the amplified view of the rectangle region in Fig. 3(d). The yellow area represents eutectic $\alpha-\mathrm{Mg}$ phase, while the red represents eutectic $\beta-\mathrm{Mg}_{17} \mathrm{Al}_{12}$ phase. It can be seen that in the solidification structure of die cast

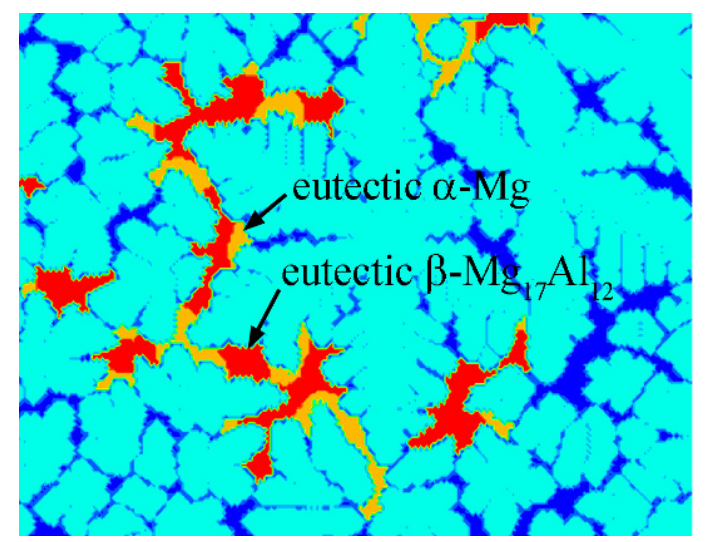

Fig. 4: Amplified view of rectangle region in Fig. 3(d) 
AM60 magnesium alloy, the $\mathrm{Mg}-\mathrm{Al}$ eutectic indeed revealed a fully divorced morphology. In other words, the eutectic $\alpha-\mathrm{Mg}$ nucleated and grew attached to the primary $\alpha-\mathrm{Mg}$, while the eutectic $\beta-\mathrm{Mg}_{17} \mathrm{Al}_{12}$ nucleated and grew independently. A conclusion can be made that the simulated results are in accordance with the die casting experimental results on the growth morphology of the $\mathrm{Mg}-\mathrm{Al}$ eutectic.

Simulations were further carried out to simulate the microstructure evolution of the $\mathrm{Mg}-\mathrm{Al}$ eutectic at the surface layer of the "cover-plate" die casting as shown in Fig. 5. The calculation domain consists of $570 \times 430$ square cells with a cell size of $0.5 \mu \mathrm{m}$. At the beginning phase of calculation, similarly, no obvious eutectic nucleation and growth were observed at the grain boundaries of primary $\alpha-\mathrm{Mg}$ [Fig. 5(a)]. As the temperature of the melt lowered, a number of nuclei of eutectic phases appeared in the interdendritic liquid as shown in Fig. 5(b). Compared with the eutectic nucleation at the central region of the"cover-plate" die casting, the number of nuclei of eutectic phases was much greater at the surface layer, since a higher cooling rate at the surface layer led to a greater nucleation undercooling of the melt. As the eutectic solidification proceeded, the eutectic phases grew continuously [Figs. 5(c) and 5(d)]. However, due to a fine and uniform grain size of primary $\alpha-\mathrm{Mg}$ at the surface layer of the "cover-plate" die casting, the eutectic phases were more dispersed and revealed a granular morphology at the grain boundaries of primary $\alpha-\mathrm{Mg}$.

\subsection{Distribution and content of Mg-Al eutectic}

Figure 6 shows an intuitive comparison between the simulated results and experimental ones regarding the distribution of the $\mathrm{Mg}-\mathrm{Al}$ eutectic at the surface and central regions of the "coverplate" die casting. It can be found that the simulated results agree well with the experimental results. The $\mathrm{Mg}-\mathrm{Al}$ eutectic reveals a more dispersed and granular morphology at the surface layer of the die casting, since the grain size of primary $\alpha-\mathrm{Mg}$ is fine and uniform. Due to the existence of ESCs which contribute to a coarse and non-uniform grain size of primary $\alpha-\mathrm{Mg}$, islands of $\mathrm{Mg}$-Al eutectic were observed at the central region of the die casting.

Quantitative statistics were conducted on the content of the eutectic $\beta-\mathrm{Mg}_{17} \mathrm{Al}_{12}$ phase in the simulated microstructure of die cast AM60 magnesium alloy, as shown in Figs. 6(a) and 6(b). The volume percentages were $3.4 \%$ and $4.5 \%$, respectively, at the surface and central regions of the die casting. Meanwhile, image analysis software Image Pro Plus was adopted to count the content of the eutectic $\beta-\mathrm{Mg}_{17} \mathrm{Al}_{12}$ phase in the metallographs of the casting by pixel color recognition and distinction. Based on experimental statistics, there was no obvious trend between the surface layer and the central region of the casting regarding the content of the eutectic $\beta-\mathrm{Mg}_{17} \mathrm{Al}_{12}$ phase, while the volume percentage was about $2 \%-6 \%$ as a whole. In this case, the simulated results were consistent with the experimental ones.
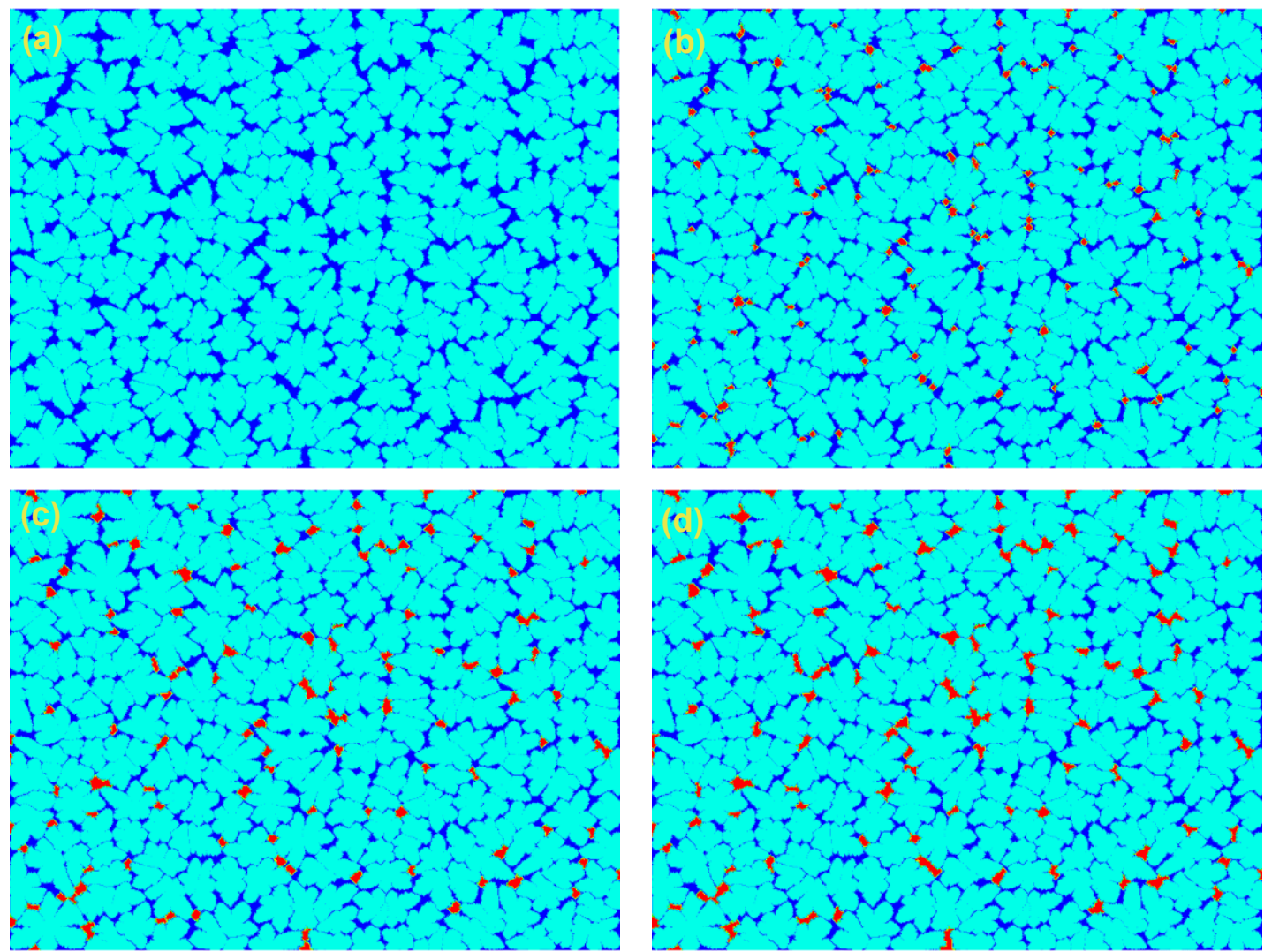

Fig. 5: Simulated microstructure evolution of Mg-Al eutectic at the surface layer of "cover-plate" die casting: (a) $0 \mathrm{~s}$, (b) $0.08 \mathrm{~s}$, (c) $0.14 \mathrm{~s}$, (d) $0.26 \mathrm{~s}$ (the time was counted at the moment when the temperature of melt went below the eutectic temperature) 

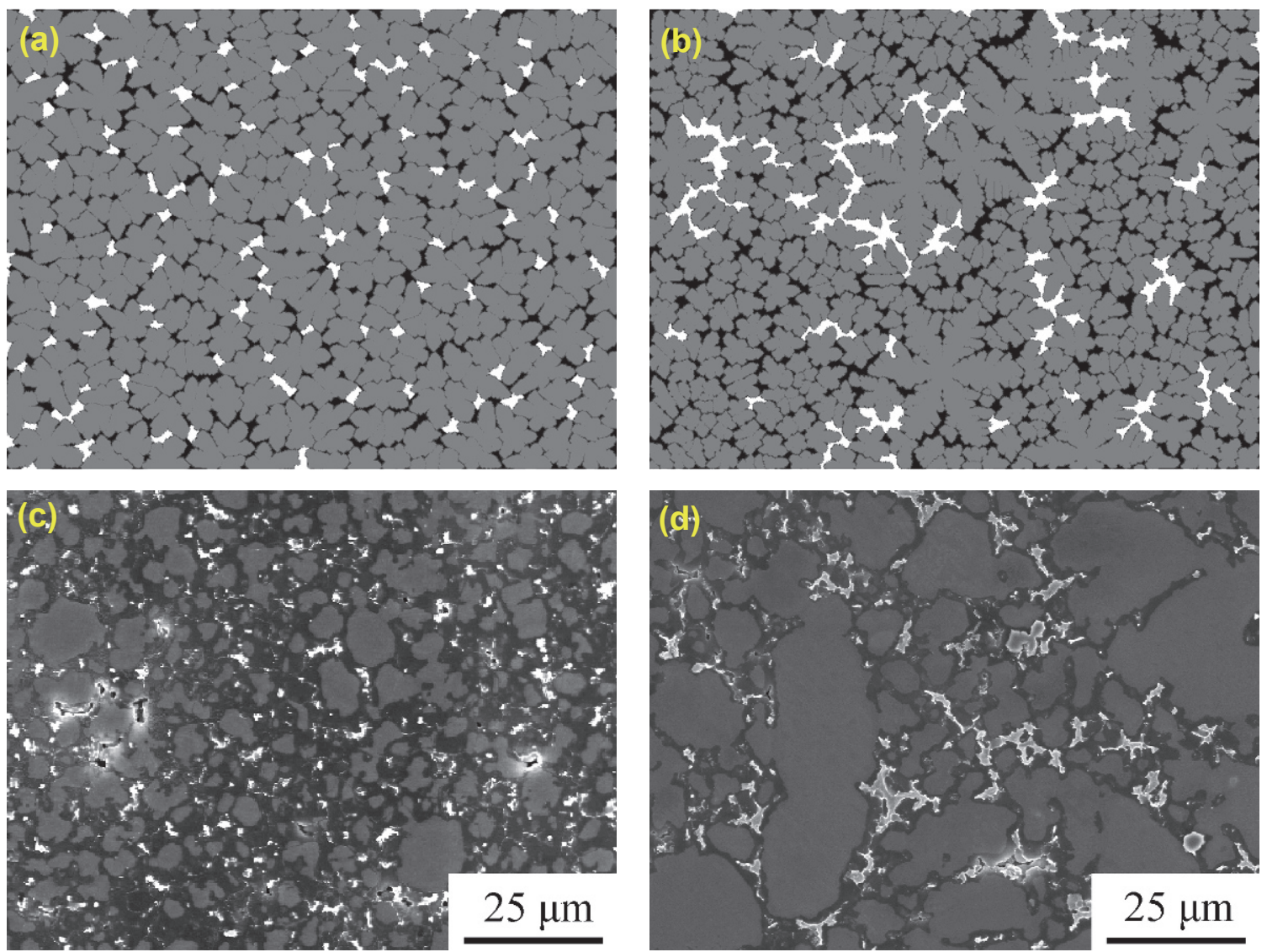

Fig. 6: Distribution of Mg-Al eutectic at surface $(a, c)$ and central $(b, d)$ regions of "cover-plate" die casting: (a-b) simulated, (c-d) experimental observed

\section{Conclusions}

(1) Using the CA method, a numerical model was developed to simulate the nucleation and growth of $\mathrm{Mg}$-Al eutectic. During the establishment of the nucleation and growth models, the nucleation density and growth velocities of the two eutectic phases were correlated with the nucleation undercooling and local undercooling of the melt, respectively.

(2) Taking the previously simulated results of dendritic growth of primary $\alpha-\mathrm{Mg}$ during solidification in the die cavity as the initial condition of the modified CA model, simulation of the divorced eutectic growth in the microstructure of die cast magnesium alloy was performed. The simulated results agreed well with the experimental ones in the morphology, distribution and content of the divorced eutectic.

(3) A high cooling rate at the surface layer of a "coverplate" die casting with AM60 magnesium alloy led to a fine and uniform grain size of primary $\alpha-\mathrm{Mg}$, which resulted in a more dispersive and granular morphology of the divorced eutectic. Meanwhile, islands of divorced eutectic were observed at the central region of the die casting, due to the existence of ESCs which contributed to a coarse and non-uniform grain size of primary $\alpha-\mathrm{Mg}$. The volume percentage of the eutectic $\beta-\mathrm{Mg}_{17} \mathrm{Al}_{12}$ phase was about $2 \%-6 \%$ in the die casting as a whole.

\section{References}

[1] Mordike B L, Ebert T. Magnesium properties-applicationspotential. Materials Science and Engineering A, 2001, 302(1): $37-45$.

[2] Abbott T. Why choose magnesium? Materials Science Forum, 2009, 618-619: 3-6.

[3] Joost W J, Krajewski P E. Towards magnesium alloys for highvolume automotive applications. Scripta Materialia, 2017, 128: 107-112.

[4] Easton M A, Zhu S M, Abbott T B, et al. Evaluation of magnesium die-casting alloys for elevated temperature applications: castability. Advanced Engineering Materials, 2016, 18(6): 953-962.

[5] Wu Mengwu, Xiong Shoumei. Microstructure characteristics of high pressure die cast AM60B magnesium alloy. Rare Metal Materials and Engineering, 2012, 41(9): 1580-1585. (In Chinese)

[6] Wang B S, Xiong S M. Effects of shot speed and biscuit thickness on externally solidified crystals of high-pressure die cast AM60B magnesium alloy. Transactions of Nonferrous Metals Society of China, 2011, 21(4): 767-772.

[7] Li X B, Xiong S M, Guo Z P. On the porosity induced by externally solidified crystals in high-pressure die-cast of AM60B alloy and its effect on crack initiation and propagation. Materials Science and Engineering A, 2015, 633: 35-41.

[8] Xiao W L, Zhu S M, Easton M A, et al. Microstructural characterization of high pressure die cast Mg-Zn-Al-RE alloys. Materials Characterization, 2012, 65: 28-36.

[9] Otarawanna S, Gourlay C M, Laukli H I, et al. Microstructure formation in AISi4MgMn and AlMg5Si2Mn high-pressure die 
castings. Metallurgical and Materials Transactions A, 2009 40(7): 1645-1659.

[10] Laukli H I, Gourlay C M, Dahle A K. Migration of crystals during the filling of semi-solid castings. Metallurgical and Materials Transactions A, 2005, 36(3): 805-818.

[11] Asta M, Beckermann C, Karma A, et al. Solidification microstructures and solid-state parallels: recent developments, future directions. Acta Materialia, 2009, 57(4): 941-971.

[12] Nastac L. Numerical modeling of solidification morphologies and segregation patterns in cast dendritic alloys. Acta Materialia, 1999, 47(17): 4253-4262.

[13] Charbon C, LeSar R. A 2D stochastic micro-macro model of equiaxed eutectic solidification. Modelling and Simulation in Materials Science and Engineering, 1997, 5(1): 53-65.

[14] Wu Mengwu, Xiong Shoumei. Microstructure simulation of high pressure die cast magnesium alloy based on modified CA method. Acta Metallurgica Sinica, 2010, 46(12): 1534-1542. (In Chinese)

[15] Wu M W, Xiong S M. Modeling of equiaxed and columnar dendritic growth of magnesium alloy. Transactions of Nonferrous Metals Society of China, 2012, 22(9): 2212-2219.

[16] Wu Mengwu, Xiong Shoumei. Experimental and modeling studies on the structure formation of high pressure die cast magnesium alloy considering the externally solidified crystals in the shot sleeve. Acta Metallurgica Sinica, 2011, 47(5): 528-534. (In Chinese)

[17] Dahle A K, Lee Y C, Nave M D, et al. Development of the ascast microstructure in magnesium-aluminium alloys. Journal of Light Metals, 2001, 1(1): 61-72.

[18] Zhao M C, Liu M, Song G L, et al. Influence of the $\beta$-phase morphology on the corrosion of the Mg alloy AZ91. Corrosion Science, 2008, 50(7):1939-1953.
[19] Dargusch M, Nave M, McDonald S D, et al. The effect of aluminium content on the eutectic morphology of high pressure die cast magnesium-aluminium alloys. Journal of Alloys and Compounds, 2010, 492(1-2): 64-68.

[20] Nagasekhar A V, Cáceres C H, Kong C. 3D characterization of intermetallics in a high pressure die cast Mg alloy using focused ion beam tomography. Materials Characterization, 2010, 61(11): 1035-1042.

[21] Wu M W, Xiong S M. Microstructure characteristics of the eutectics of die cast AM60B magnesium alloy. Journal of Materials Science and Technology, 2011, 27(12): 1150-1156.

[22] Zhang Lei, Zhao Honglei, Zhu Mingfang. Simulation of solidification microstructure of spheroidal graphite cast iron using a cellular automaton method. Acta Metallurgica Sinica, 2015, 51(2): 148-158. (In Chinese)

[23] Zhu M F, Zhang L, Zhao H L, et al. Modeling of microstructural evolution during divorced eutectic solidification of spheroidal graphite irons. Acta Materialia, 2015, 84: 413-425.

[24] Xiong S M, Wu M W. Experimental and modeling studies of the lamellar eutectic growth of Mg-Al alloy. Metallurgical and Materials Transactions A, 2012, 43(1): 208-218.

[25] Trivedi R, Magnin P, Kurz W. Theory of eutectic growth under rapid solidification conditions. Acta Metallurgica, 1987, 35(4): 971-980.

[26] Zhu M F, Hong C P. Modeling of microstructure evolution in regular eutectic growth. Physical Review B, 2002, 66(15): 155428.

[27] Magnin P, Kurz W. An analytical model of irregular eutectic growth and its application to Fe-C. Acta Metallurgica, 1987 , 35(5): 1119-1128.

[28] Himemiya T, Ohsasa K, Saga T. Eutectic growth model using cell-automaton method. Materials Transactions, 2010, 51(1): $110-115$

This work was financially supported by the Fundamental Research Funds for the Central Universities (WUT:2017IVA036), 111 Project (B17034) and State Key Laboratory of Materials Processing and Die \& Mould Technology, Huazhong University of Science and Technology (P2018-003). 